\title{
Improved Permeate Flux and Rejection of Ultrafiltration Membranes Prepared From Polyethylene Terephthalate (PET) Bottle Waste
}

Samuel P Kusumocahyo ( $\nabla$ samuel.kusumocahyo@sgu.ac.id )

Swiss German University https://orcid.org/0000-0001-9336-9533

Syarifa K. Ambani

Swiss German University

Shelly Marceline

Swiss German University

\section{Research}

Keywords: Ultrafiltration membrane, polyethylene terephthalate (PET), plastic bottle, recycle, water treatment

Posted Date: February 9th, 2021

DOI: https://doi.org/10.21203/rs.3.rs-174726/v1

License: (c) (i) This work is licensed under a Creative Commons Attribution 4.0 International License. Read Full License 


\section{Abstract}

Polyethylene terephthalate (PET) ultrafiltration membranes were prepared using two different sources of polymer material, namely PET bottle waste and PET resin. The membrane prepared from PET bottle waste and that prepared from PET resin showed similar membrane characteristics such as IR spectra, morphology, hydrophilicity and porosity, indicating that instead of using PET resin, PET bottle waste can be utilized as a source of the polymer material to fabricate low-cost membranes. The morphology, hydrophilicity and porosity of the membranes were strongly affected by the additive concentration. The analysis of the membrane morphology using Scanning Electron Microscopy (SEM) showed that the membranes had an asymmetric structure that consists of a macroporous cross section and a smooth active layer. Increasing the additive concentration of polyethylene glycol (PEG 400) resulted in a smaller pore size, however the hydrophilicity and the porosity of the membranes increased. As a result, the membranes showed an increase in both permeate flux and rejection with increasing concentration of PEG 400 as observed from the results of the ultrafiltration experiments. Using Bovine Serum Albumin as a solute model in the feed, high values of rejection of up to $93.9 \%$ were achieved.

\section{Introduction}

Ultrafiltration membranes are widely used for separation processes of aqueous solutions in various industries such as food, dairy, beverage, pharmaceutical, textile, electronics, and chemical industries. They are mostly applied for water treatment such as the production of pure water to remove microorganisms, bacteria, virus, colloidal substances, and suspended micro particles from the water [1, 2]. Other application of ultrafiltration membranes is for the concentration of protein or enzyme $[3,4]$. Ultrafiltration membranes have usually a porous asymmetric structure with a macroporous cross section and a smooth active layer that is able to reject high molecular weight solutes such as protein, virus, bacteria, etc., whereas water or low molecular weight solutes can permeate through the membrane. The separation using the ultrafiltration membrane is a pressure-driven separation process, which can be simply operated using a pump without the use of heat. Therefore, the use of the ultrafiltration membrane for separation processes has many advantages due to the lower energy consumption and the high selectivity.

Commercial ultrafiltration membranes available in the market are usually made from cellulose acetate, polysulfone, polyethersulfone or polyvinylidene fluoride. Many studies to develop ultrafiltration membranes using other polymer materials such as polyetherimide, polyvinyl chloride, chitosan, and other materials have been reported $[5,6,7]$. Studies on the modification of the membranes to improve the permeate flux and the rejection have also been reported $[1,8,9]$. Recently, our previous study on the use of polyethylene terephthalate (PET) bottles to prepare PET ultrafiltration membranes have been reported [10]. PET packaging is widely used by the food and beverage industries because of its excellent mechanical strength, good chemical resistance, good transparency, and excellent gas-barrier resistance. PET films are also suitable for many other applications due to their excellent mechanical properties [11, 12], and good chemical resistance against acids and low concentration of alkalies [13]. The outstanding 
mechanical and chemical properties of PET open the opportunity to fabricate ultrafiltration membranes from PET. The source of the polymer material even can be found in used PET bottles or other used PET packaging that are usually considered as waste. In our previous study on the development of ultrafiltration membranes using PET bottle waste, it was observed that the permeate fluxes increased by decreasing the polarity of the non-solvent, by increasing the molecular weight of the additive, or by increasing the additive concentration [10]. However, it was observed that the permeate flux enhancement was followed by a decline of the rejection rate, because of the enlargement of the membrane pore size. The same phenomenon has been also reported in other studies [5, 14]. Ultrafiltration membranes with high permeate fluxes are desired since the ultrafiltration membranes have been known to have a drawback, namely fouling problem, that is the permeate flux decline with the operating time because of the concentration polarization on the surface of the membranes. In order to eliminate fouling, many studies have been done to develop membranes with improved permeate fluxes $[1,7,8,9]$. However, the increase in the permeate flux is usually followed with the decrease in the rejection of the membranes. Thus, it is very crucial to develop ultrafiltration membranes with improved permeate flux without any decrease in the rejection.

The objective of this work is to develop PET ultrafiltration membranes which exhibit improved permeate fluxes with high rejection values. The membranes were developed using PET bottle waste as the polymer material using polyethylene glycol with molecular weight of $400 \mathrm{Da}$ (PEG 400) as the additive. The aim of the utilization of PET bottle waste is also to give a contribution in the plastic recycling to reduce plastic waste. Since PET bottles are originally produced from PET resin, PET resin was also used in this work as the polymer material to prepare the membranes with the aim to compare the characteristics of the membrane developed from PET bottles and that from PET resin. The effect of the PEG 400 concentration on the microstructure, the hydrophilicity and the porosity of the membranes was studied by using Scanning Electron Microscopy (SEM), water contact angle measurement, and gravimetric method, respectively. The membranes were characterized using Fourier Transform Infrared (FTIR) spectroscopy to study the chemical properties. Furthermore, the membranes were characterized for their ultrafiltration performances through ultrafiltration experiments using pure water and a feed solution containing Bovine Serum Albumin (BSA) molecules (MW: 66,000 Da) as a feed model.

\section{Materials And Methods 2.1. Materials}

Plastic bottles made from polyethylene terephthalate (PET) were used. The PET bottles were previously used as packaging for mineral water and was obtained from the local supermarket in Indonesia. PET resin was also used as the polymer material, and was manufactured and supplied by PT Indorama Ventures Indonesia. Phenol ( $\geq 99 \%$ ) was used as the solvent, and was supplied by Merck, Germany. Lowmolecular weight of polyethylene glycol (PEG 400) was used the additive, and was supplied by Merck, Germany. Bovine serum albumin (BSA, molecular weight: 66,000 Da) was also supplied by Merck, Germany. Technical grade ethanol (96\%), monosodium phosphate (NaH2PO4, $\geq 99 \%$ ), disodium 
phosphate ( $\mathrm{Na} 2 \mathrm{HPO} 4, \geq 99 \%)$, potassium chloride $(\mathrm{KCl}, \geq 99 \%)$, and sodium chloride $(\mathrm{NaCl}, \geq 99 \%)$ were all supplied by Merck, Germany. All chemicals were used as received. Distilled deionized water was used.

\subsection{Preparation of PET membranes}

After removing the labels and bottle caps, the bottles were thoroughly washed. The clean and dry bottles were then cut to obtain small PET shards. PET resin was also used as the membrane material with the aim to compare the characteristics of the membranes with that prepared from the used PET bottles. To prepare the casting solution, phenol was heated at $40^{\circ} \mathrm{C}$ to liquify it as phenol is a solid at room temperature. Then, the PET bottle shards or the PET resins were added into the phenol under continuous stirring and heating at $100^{\circ} \mathrm{C}$ using a hot plate (Barnstead Thermolyne) equipped with a magnetic stirrer. Meanwhile, a solution of PEG 400 in phenol was prepared separately by dissolving PEG 400 in phenol at the same condition as above. Both polymer solutions were then mixed at $100^{\circ} \mathrm{C}$ for one hour under continuous stirring to obtain a homogeneous polymer solution. The composition of the PET, the PEG 400 and the solvent in the casting solutions can be seen in Table 1. The membranes were then prepared from the casting solutions by the phase-inversion technique. The polymer solution was cast onto a glass plate and then submerged in a non-solvent bath containing solution of water-ethanol $(1: 12 \mathrm{v} / \mathrm{v})$ at room temperature. As a result, a white solid flat membrane was obtained. After rinsing several times using distilled deionized water, the membranes were stored in plastic containers containing distilled deionized water for further use.

Table 1

Composition of the membrane casting solutions

\begin{tabular}{|lll|}
\hline Membrane Casting Solution & $\begin{array}{l}\text { Weight Ratio of } \\
\text { PET : phenol : PEG 400 }\end{array}$ & $\begin{array}{l}\text { PEG } 400 \\
\text { Concentration (wt\%) }\end{array}$ \\
\hline Membrane PET bottle & $4: 20: 0$ & 0 \\
\hline Membrane PET resin & $4: 20: 0$ & 0 \\
\hline Membrane PET-PEG-1.25 & $4: 20: 1.25$ & 4.95 \\
\hline Membrane PET-PEG-1.5 & $4: 20: 1.5$ & 5.88 \\
\hline Membrane PET-PEG-2 & $4: 20: 2$ & 7.69 \\
\hline Membrane PET-PEG-3 & $4: 20: 3$ & 11.11 \\
\hline
\end{tabular}

\subsection{Characterization of PET membranes}

These flat-sheet membranes were characterized for their average thicknesses using a micrometer (Tricle, China) from the measurement of five different locations of the membrane. Analysis using Fourier Transform Infrared spectroscopy was conducted to study the chemical structure of the membranes using FTIR spectrometer (Shimadzu IR Prestige-21, Japan). Analysis using Scanning Electron Microscopy 
(SEM, Quanta 650) was conducted to study the microstructures of the membranes. Gravimetric method was used to determine the membrane porosity using the following equation $[15,16]$ :

$$
\varepsilon=\frac{\left(w_{1}-w_{2}\right) / d_{w}}{\left(\left(w_{1}-w_{2}\right) / d_{w}\right)+w_{2} / d_{p}}
$$

where $w_{1}$ and $w_{2}$ are the weight of the wet membrane and that of the dry membrane, respectively, whereas $d_{w}$ and $d_{p}$ are the density of the water and that of the polymer, respectively. The wet membrane was obtained by immersing the membrane in distilled deionized water at room temperature for $24 \mathrm{~h}$, while the dry membrane was obtained by drying the membrane in an oven at $110^{\circ} \mathrm{C}$ for $3 \mathrm{~h}$. Five membrane samples were used to obtain the average value of the porosity. The membranes were characterized for their hydrophilicity by measuring the water contact angle using a water contact angle meter (Face CA-D, Kyowa Kaimengaku, Japan). The measurement was conducted using distilled deionized water at room temperature, and repeated six times to obtain the average value of the contact angle.

\subsection{Measurement of permeate flux and rejection through ultrafiltration experiment}

Ultrafiltration experiments were performed to measure the pure water permeate flux using distilled deionized water as the feed that was pumped through a membrane cell. The membrane cell had an effective area of $51.8 \mathrm{~cm} 2$. The experiment was conducted in a cross-flow mode at a trans-membrane pressure of 1 bar at room temperature. The permeate flux $F$ was determined from the weight of the collected permeate $m_{p}$ divided by the membrane area $A$ and the time interval $\Delta t$ using the equation below:

$$
F=\frac{m_{p}}{A \Delta t}
$$

The membranes were then characterized for their ability to reject macromolecules through ultrafiltration experiments using an aqueous phosphate buffered-saline solution containing 1000 ppm BSA. The method to prepare the phosphate buffered-saline solution can be found elsewhere [10]. To determine the rejection $\mathrm{R}$, the following equation was used:

$$
R=\left(1-\frac{c_{P}}{c_{F}}\right) \times 100 \%
$$

where $C_{F}$ and $C_{P}$ are the concentration of BSA in the feed solution and that in the permeate, respectively. A UV-vis spectrophotometer ( $P G$ instrument T-60, UK) was used to measure the BSA concentration at a wavelength of $280 \mathrm{~nm}$.

\section{Results And Discussion}




\subsection{Comparison of membranes prepared from used PET bottles and PET resin}

It has been known that the morphology of a membrane prepared by using the phase-inversion technique is strongly affected by the polymer, the solvent, the non-solvent and the additive. In this study, the polymer used to prepare the membranes was polyethylene terephthalate (PET). Two different sources of the polymer material were used, namely used PET bottles and PET resin which is the raw material to produce the PET bottles. Since used PET bottles are considered as waste, it is important to compare the characteristics of the membrane developed from the PET bottles and that prepared from the PET resin. The FTIR spectra of the PET membrane developed from the PET bottles are shown in Fig. 1, whereas that of the membrane from PET resin are shown in Fig. 2. Both membranes were prepared without additive. As can be seen, both membranes showed similar IR spectra, indicating that there is no difference in the chemical structure of the membrane from the used PET bottles and that from the PET resin. The FTIR spectra of both membranes are similar to the spectra of PET films that have been analyzed by other studies $[17,18]$. Figure 2 shows the chemical structure of PET, whereas the interpretation of the FTIR spectra of both PET membranes is listed in Table 2.

Table 2

Interpretation of FTIR spectra of membranes from PET bottle and PET resin

\begin{tabular}{|lll|}
\hline No & Wavenumber $(\mathbf{1 / \mathrm { cm }})$ & Functional Group \\
\hline 1 & 3054 & C-H bond of the phenyl ring \\
\hline 2 & $2967-2969$ & C-H bond of the ethyl group \\
\hline 3 & 2907 & C = O bond of the ester group \\
\hline 4 & $1742-1743$ & C = O bond of the ester group \\
\hline 5 & $1578-1579$ & C-H bond of the phenyl ring \\
\hline 6 & $1504-1506$ & C = C bond of the phenyl ring \\
\hline 7 & $1413-1415$ & C-C bond of the phenyl ring \\
\hline 8 & $1140-1142$ & C-O bond of the ester group \\
\hline 9 & 1024 & C-O bond of the ester group \\
\hline 10 & $737-738$ & C-H bond of the ethyl group \\
\hline
\end{tabular}

Furthermore, the microstructure of the membrane was analyzed by using Scanning Electron Microscopy (SEM). Figure 4 and Fig. 5 show the SEM images of the cross section and surface of the membrane from used PET bottles and that from PET resin, respectively. No additive was used to prepare both membranes. Both membranes had an asymmetric structure that consists of a macroporous cross section and a 
smooth surface as the active layer of the membrane. There was almost no difference between the morphology of the membrane from used PET bottles and that from PET resin. This finding is in accordance with the FTIR analysis of both membranes that showed no difference of the FTIR spectra as described previously.

The membranes had an average thickness of $149 \pm 13 \mu \mathrm{m}$ as measured using a micrometer. Furthermore, the porosity and the water contact angle of both membranes are listed in Table 3. There was no significant difference between the porosity of both membranes. Both membranes also showed almost the same hydrophilicity as measured using the water contact angle method. Again, these results are in agreement with the results of FTIR analysis and SEM analysis as described previously.

Since both membranes prepared from used PET bottle and PET resin exhibited the same properties such as the chemical structure, the microstructure, the porosity and the hydrophilicity as described above, it can be concluded that instead of using PET resin, used PET bottles that are usually considered as waste can be utilized as the source of the polymer material to prepare the PET ultrafiltration membranes. The utilization of used PET bottles is advantageous since it will not only reduce the cost of the membrane material, but also will contribute in the efforts of plastic recycling process for a sustainable environment.

Table 3

Comparison of porosity and water contact angle of the membrane from PET bottle and that from PET resin without additive

\begin{tabular}{|llll|}
\hline Membrane & Polymer source & $\begin{array}{l}\text { Porosity } \\
(\%)\end{array}$ & Water Contact Angle $\left(^{\circ}\right)$ \\
\hline Membrane - PET bottle & Used PET bottle & $69.7 \pm 0.5$ & $65.5 \pm 1.4$ \\
\hline Membrane - PET resin & PET resin & $71.0 \pm 1.2$ & $65.8 \pm 1.1$ \\
\hline
\end{tabular}

\subsection{Effect of PEG 400 concentration on the microstructure, hydrophilicity and porosity}

The use of additives for the preparation of membrane by using the phase inversion technique has been known to be effective to achieve the desired membrane characteristics such as microstructure, hydrophilicity, porosity, and flexibility [19]. In this study, polyethylene glycol with a molecular weight of $400 \mathrm{Da}$ (PEG 400) was used as the additive. PEG has been known as a pore forming agent, a pore reducer, and a plasticizer for various polymers $[19,20,21]$. In this work, low-molecular weight PEG such as PEG 400 was chosen as the additive for the PET membranes since our previous study revealed that the use of high molecular weights of PEG such as PEG 4000 resulted in the membranes with too large pore size that decreased the rejection rate of the membranes [10]. Figure 6 and Fig. 7 show the SEM images of the cross section and surface of the membranes with various concentrations of PEG 400 . All of the membranes were prepared using PET bottles as the polymer material. All membranes showed an 
asymmetric structure that consists of a macroporous cross section and a smooth surface as the active layer. Interestingly, the morphology of the membranes changed as the formation of the pores was influenced by the PEG 400 concentration. It can be observed from the SEM images that the increment of the PEG 400 concentration resulted in a smaller pore size of the membrane cross section. It has been known that low-molecular weight PEG such as PEG 400 acts as a pore reducer for various polymer membranes $[5,19]$. The formation of pores occurred when the casted polymer solution consisting of PET, phenol (the solvent) and PEG 400, was immersed in the water-ethanol as the non-solvent. Due to the solvent and non-solvent exchange, precipitation took place, and PEG 400 acted as a pore reducer for the membrane. The growth of the pore formation was hindered when the membrane contained a high concentration of PEG 400. As a result, the pore size of the of the membrane cross section decreased with increasing concentration of PEG 400.

Furthermore, Fig. 8 shows the effect of the PEG 400 concentration on the membrane porosity. It can be obviously seen that the porosity of the PET membrane increased by the addition of PEG 400 as the additive. The porosity of the PET membrane without additive was $69.7 \% \pm 0.5 \%$, and the porosity increased sharply to $79.4 \% \pm 0.3 \%$ through the addition of $4.95 \mathrm{wt} \%$ of PEG 400 . A further increase in the porosity with increasing PEG 400 concentration was observed, and then the value of the porosity became stable at high concentrations of PEG 400. High values of porosity of $82.4 \% \pm 0.4 \%$ and $82.2 \pm 0.2 \%$ were achieved by adding $7.69 \mathrm{wt} \%$ and $11.11 \mathrm{wt} \%$ of PEG 400 , respectively. This phenomenon occurred since PEG 400 acted as pore former that increased the membrane porosity as described above.

Figure 9 shows the effect PEG 400 concentration on the water contact angle of the membranes. It can be seen obviously that the water contact angle decreased significantly with increasing concentration of PEG 400. This indicated that the hydrophilicity of the membranes increased. The hydrophilic characteristic of PEG was effective to increase the hydrophilicity of the membranes. Other studies have reported a similar phenomenon for polysulfone and polyethersulfone membranes that showed an increase in the hydrophilicity by the addition of polyethylene glycol as the additive [19]. The increase in the porosity and the hydrophilicity is desired as the ultrafiltration membranes are mostly applied for water treatment.

\subsection{Results of ultrafiltration experiment using PET membranes}

\subsubsection{Comparison of ultrafiltration performance of the membrane from PET bottle and that from PET resin}

The membranes prepared from used PET bottle and that from PET resin were then tested through ultrafiltration experiments to measure the permeate flux of pure water. The membranes prepared from PET bottle and that from PET resin with the addition of PEG 400 showed a good flexibility, since PEG acted as a plasticizer for the membranes $[20,21]$. However, the membrane developed from used PET bottle and that from PET resin without PEG 400 were so stiff that they could not be fitted in the membrane cell for the ultrafiltration experiment. Figure 10 shows the permeate flux of pure water for the 
membrane developed from PET bottle in comparison with that from PET resin using PEG 400 as the additive. Both membranes were prepared using the same PEG 400 concentration of $11.1 \mathrm{wt} \%$. It can be seen that both membranes exhibited almost the same values and profiles of water permeate fluxes as a function of the permeation time. In the beginning, the water permeate fluxes decreased with time, then they became stable after around 2 hours. The decline of the permeate flux with time was caused by the physical compaction of the newly prepared membranes. The phenomenon of the physical compaction of polymer membranes has been also found in many other membranes [22, 23, 24, 25]. As described previously, both membranes prepared from PET bottle and PET resin showed similar membrane properties such as morphology, porosity and hydrophilicity. The similar membrane properties of both membranes resulted in similar permeate flux during the ultrafiltration experiment. This result revealed that instead of using PET resin as the source of the polymer, the PET ultrafiltration membranes could be prepared using PET bottle waste. Since PET bottle waste needs to be recycled, the conversion of used PET bottles into PET ultrafiltration membranes has great potential in the contribution for the environment conservation.

\subsubsection{Ultrafiltration performances of PET membranes with different PEG 400 concentrations}

To study the influence of additive concentration on the ultrafiltration performance, the membranes that were prepared from PET bottles with the addition of various concentrations of PEG 400 were tested through ultrafiltration experiments. Figure 11 shows the permeate fluxes of pure water for the membranes prepared from PET bottle with various PEG 400 concentrations. The membranes showed a decline of the permeate flux in the beginning of the permeation time, and then the permeate flux became stable after around $2 \mathrm{~h}$, because of the physical compaction as described above. Interestingly, the membranes showed an increment of the permeate flux when the PEG 400 concentration was increased. It can be seen that the membrane with a low PEG 400 concentration of $4.95 \mathrm{wt} \%$ exhibited the lowest water permeate flux. The permeate flux increased sharply as the PEG 400 concentration was increased to $5.88 \mathrm{wt} \%$ and $7.69 \mathrm{wt} \%$. A further increase in the PEG concentration of $11.11 \mathrm{wt} \%$ resulted in the highest permeate flux, however in the steady state condition the permeate flux values became almost the same with that of the membrane with PEG 400 concentration of $7.69 \mathrm{wt} \%$. This result is in agreement with the results of the membrane characterization as explained previously. The increment of the permeate flux with increasing concentration of PEG 400 was caused by the increase in the hydrophilicity and the porosity of the membranes. As described previously, the PET membrane without PEG 400 showed a low hydrophilicity. When PEG 400 was introduced into the PET, the membrane became more hydrophilic, and water was attracted stronger onto the membrane, resulting in a higher water permeate flux. At the same time, the increment of the PEG 400 concentration also increased the membrane porosity, resulting in an increment of the permeate flux.

Furthermore, the membranes were tested through ultrafiltration experiments using an aqueous feed solution containing 1000 ppm BSA. The permeate samples were collected after attaining a steady state condition, and the rejection was determined from the BSA concentration in the permeate and that in the 
feed using the Eq. (3). Table 4 depicts the results of the experiments, showing the BSA rejection of the PET membranes prepared with different PEG 400 concentrations. The membrane with a PEG 400 concentration of $4.95 \mathrm{wt} \%$ showed a low rejection value of $61 \%$, and the rejection increased by increasing the PEG 400 concentration. A high value of rejection rate of $93.9 \%$ was achieved by the membrane having PEG 400 concentration of $11.11 \mathrm{wt} \%$. This result is very interesting since the increment of the permeate flux did not decrease the rejection as usually observed in the development of ultrafiltration membranes as reported in many studies $[5,14]$. Here, the PET membranes exhibited an increase in both permeate flux and rejection when more PEG 400 was added into the membranes. A similar phenomenon has also been observed by Eren et al., 2015 [24], who reported an improvement of both permeate flux and BSA rejection of polysulfone membrane containing hydrophilic modifiers. In this work, the increment of the rejection rate of the PET membranes with increasing PEG 400 concentration was caused by the decrease in the pore size of the membranes as revealed by the results of the SEM analysis, whereas the increment of the permeate flux was caused by the increase in the hydrophilicity and the porosity of the membranes. A high hydrophilicity resulted in a strong sorption of water to the membranes, whereas a high porosity increased the diffusivity of water through the membrane.

Table 4

Rejection of BSA molecules for PET membranes with different concentrations of PEG 400

\begin{tabular}{|lll|}
\hline Membrane & PEG 400 Concentration (wt\%) & $\begin{array}{l}\text { Rejection } \\
(\%)\end{array}$ \\
\hline Membrane PET-PEG 1.25 & 4.95 & 61.0 \\
\hline Membrane PET-PEG 1.5 & 5.88 & 73.2 \\
Membrane PET-PEG 2 & 7.69 & 90.6 \\
Membrane PET-PEG 3 & 11.11 & 93.9 \\
\hline
\end{tabular}

\section{Conclusions}

The ultrafiltration membrane prepared from used PET bottles showed the same chemical property, morphology, porosity and hydrophilicity with that prepared from PET resin, indicating that instead of using PET resin, used PET bottles that are considered as waste can be utilized as a polymer source to prepare the PET membranes. The use of additive PEG 400 for the PET membranes increased the porosity and the hydrophilicity of the membranes, but decreased the membrane pore size as observed by the SEM analysis. As a result, both permeate flux and rejection of the PET membranes were improved by increasing the PEG 400 concentration. A high value of BSA rejection of $93.9 \%$ was attained using the membrane prepared from PET bottles with the PEG 400 concentration of $11.11 \mathrm{wt} \%$. The result of this study revealed that the low cost ultrafiltration membranes with improved permeate flux and rejection could be prepared from used PET bottles as the polymer material with the addition of PEG 400 as the 
additive. The PET membranes have great potential to be applied for water treatment processes and to contribute in the environment conservation through the recycling of PET bottle waste.

\section{Declarations}

\section{Competing interests}

The authors declare they have no competing interests.

\section{Funding}

This work was financially supported by the Ministry of Research and Technology of the Republic of Indonesia through the WCR research grant program 2019/2020.

\section{Authors' contributions}

Samuel P. Kusumocahyo conducted conceptualization, methodology, supervision, writing, review and editing. Syarifa K. Ambani conducted investigation and visualization. Shelly Marceline conducted investigation, data curation, formal analysis and validation. All authors read and approved the final manuscript.

\section{Acknowledgements}

The authors wish to thank the Ministry of Research and Technology of the Republic of Indonesia for the financial support for this work through the WCR research grant program 2019/2020.

\section{References}

1. Xu Z., Wu T., Shi J., Teng K., Wang W., Ma M., Li J., Qian X., Li C., Fan J., Photocatalytic antifouling PVDF ultrafiltration membranes based on synergy of graphene oxide and TiO2 for water treatment, J. Membr. Sci. 2016, 520, 281-293

2. Benitez F.J., Acero J.L., Real F.J., Garcia C., Removal of phenyl-urea herbicides in ultrapure water by ultrafiltration and nanofiltration processes, Water Res. 2009, 43, 267-276

3. Yee K.W.K., Wiley D.E., Bao J., Whey protein concentrate production by continuous ultrafiltration: Operability under constant operating conditions, J. Membr. Sci. 2007, 290/1-2, 125-137

4. Enevoldsen A.D., Hansen E.B., Jonsson G., Electro-ultrafiltration of industrial enzyme solutions, J. Membr. Sci. 2007, 299/1-2, 28-37

5. Kim I.-C., Lee K.-H., Effect of poly(ethylene glycol) 200 on the formation of a polyetherimide asymmetric membrane and its performance in aqueous solvent mixture permeation, J. Membr. Sci. 
$2004,230,183-188$

6. Mokhena T.C., Luyt A.S., Development of multifunctional nano/ultrafiltration membrane based on a chitosan thin film on alginate electrospun nanofibres, J. Clean. Prod. 2017, 156, 470-479

7. Yong M., Zhang Y., Sun S., Liu W., Properties of polyvinyl chloride (PVC) ultrafiltration membrane improved by lignin: Hydrophilicity and antifouling, J. Membr. Sci. 2019, 575, 50-59

8. Rana D., Matsuura T., Surface modifications for antifouling membranes, Chem. Rev. 2010, 110/4, 2448-2471

9. Zhang M., Field R.W., Zhang K., Biogenic silver nanocomposite polyethersulfone UF membranes with antifouling properties, J. Membr. Sci. 2014, 471/1, 274-284

10. Kusumocahyo S.P., Ambani S.K., Kusumadewi S., Sutanto H., Widiputri D.I., Kartawiria I.S., Utilization of used polyethylene terephthalate (PET) bottles for the development of ultrafiltration membrane, J. Environ. Chem. Eng. 2020, 8, 104381

11. Horvath T., Kalman M., Szabo T., Roman K., Zsoldos G., Szabone Kollar M.S., The mechanical properties of polyethylene-terephthalate (PET) and polylactic-acid (PDLLA and PLLA), the influence of material structure on forming, IOP Conf. Ser.: Mater. Sci. Eng. 2018, 426, 012018

12. Bin Y., Oishi K., Yoshida K., Matsuo M., Mechanical Properties of Poly(ethylene terephthalate) Estimated in Terms of Orientation Distribution of Crystallites and Amorphous Chain Segments under Simultaneous Biaxially Stretching, Polym. J. 2004, 36/11, 888-898

13. Polyguard, Technical Bulletin - Chemical Resistance of PET/polyester Films 2015, https://www.polyguardproducts.com

14. Wu T., Zhou B., Zhu T., Shi J., Xu Z., Hu C., Wang J., Facile and low-cost approach towards PVDF ultrafiltration membrane with enhanced hydrophilicity and antifouling performance via graphene oxide / water-bath coagulation, RSC Adv. 2015, 5, 7880-7889

15. Hamid N.A.A., Ismail A.F., Matsuura T., Zularisam A.W., Lau W.J., Yuliwati E., Abdullah M.S., Morphological and separation performance study of polysulfone/titanium dioxide (PSF/TiO2) ultrafiltration membranes for humic acid removal, Desalination 2011, 273, 85-92

16. Li J.H., Xu Y.Y., Zhu L.P., Wang J.H., Du C.H., Fabrication and characterization of a novel TiO2 nanoparticles self-assembly membrane with improved fouling resistance, J. Membr. Sci. 2009, $326 / 2,659-666$

17. El-Saftawy A.A., Elfalaky A., Ragheb M.S., Zakhary S.G., Electron beam induced surface modifications of PET film, Radiat. Phys. Chem. 2014, 102, 96-102

18. Pereira A.P.d.S., da Silva M. H. P., Júnior É. P. L., Paula A.d.S., Tommasini F. J., Processing and Characterization of PET Composites Reinforced With Geopolymer Concrete Waste, Mater. Res. 2017, 20/2, https://doi.org/10.1590/1980-5373-mr-2017-0734

19. Liu Y., Koops G.H., Strathmann H., Characterization of morphology controlled polyethersulfone hollow fiber membranes by the addition of polyethylene glycol to the dope and bore liquid solution, $\mathrm{J}$. Membr. Sci. 2003, 223, 187-199 
20. Cao N., Yang X., Fu Y., Effects of various plasticizers on mechanical and water vapor barrier properties of gelatin films, Food Hydrocoll. 2009, 23/3, 729-735

21. Oh H.J., Freeman B.D., McGrath J.E., Ellison C.J., Mecham S., Lee K-S., Paul D.R., Rheological studies of disulfonated poly (arylene ether sulfone) plasticized with poly (ethylene glycol) for membrane formation, Polymer 2014, 55/6, 1574-1582

22. Mahendran R., Malaisamy R., Mohan D., Preparation, characterization and effect of annealing on performance of cellulose acetate/sulfonated polysulfone and cellulose acetate/epoxy resin blend ultrafiltration membranes, Eur. Polym. J. 2004, 40/3, 23-633

23. Pendergast M.T.M., Nygaard J.M., Ghosh A.K., Hoek E.M.V., Using nanocomposite materials technology to understand and control reverse osmosis membrane compaction, Desalination 2010, $261 / 3,255-263$

24. Eren E., Sarihan A., Eren B., Gumus H., Kocak F.O., Preparation, characterization and performance enhancement of polysulfone ultrafiltration membrane using PBI as hydrophilic modifier, J. Membr. Sci. $2015,475,1-8$

25. Arthanareeswaran G., Sriyamuna Devi T.K., Raajenthiren M., Effect of silica particles on cellulose acetate blend ultrafiltration membranes: Part I, Sep. Purif. Technol. 2008, 64, 38-47

\section{Figures}




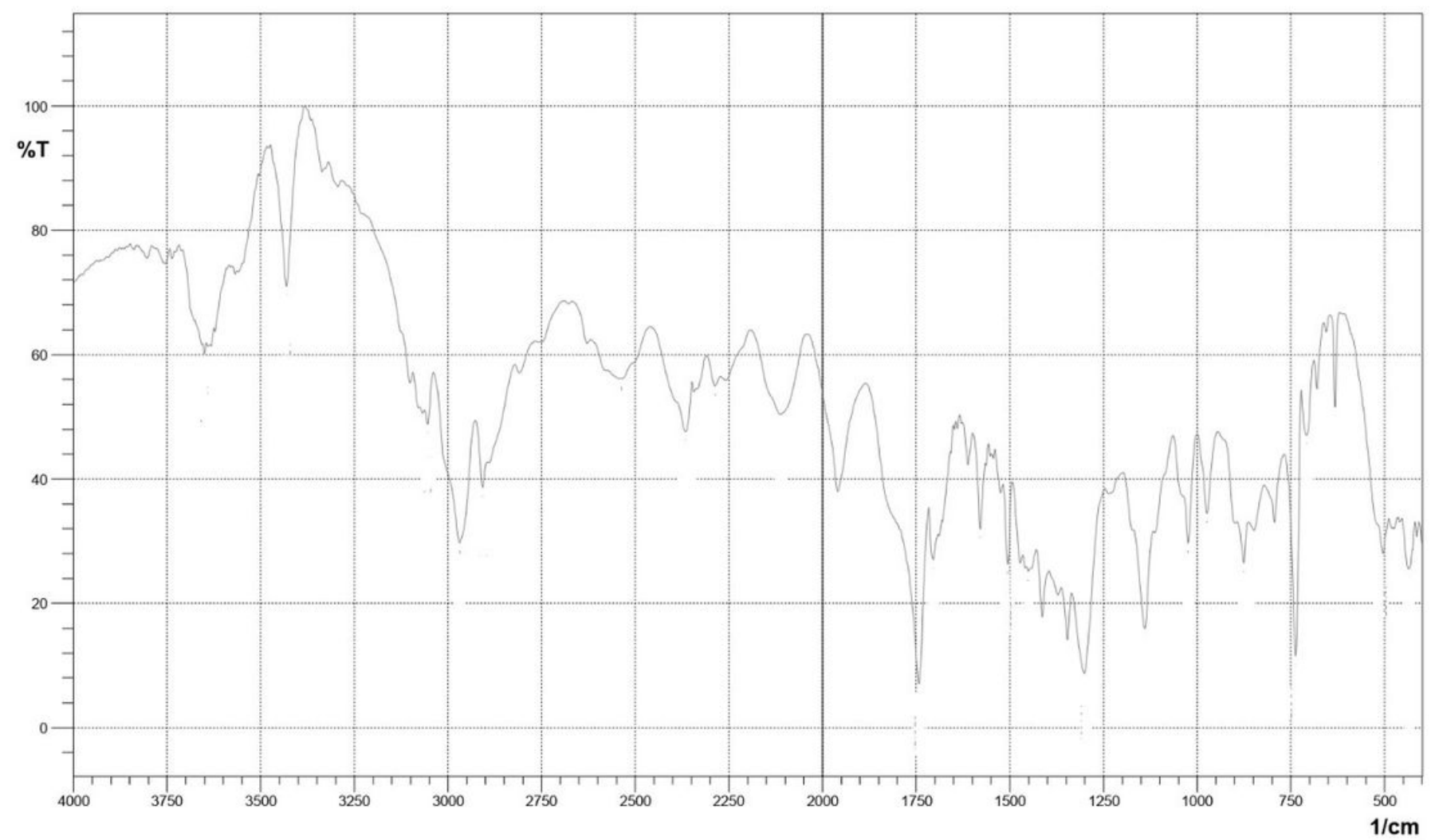

Figure 1

FT-IR spectra of PET membrane using PET bottles as the polymer source 


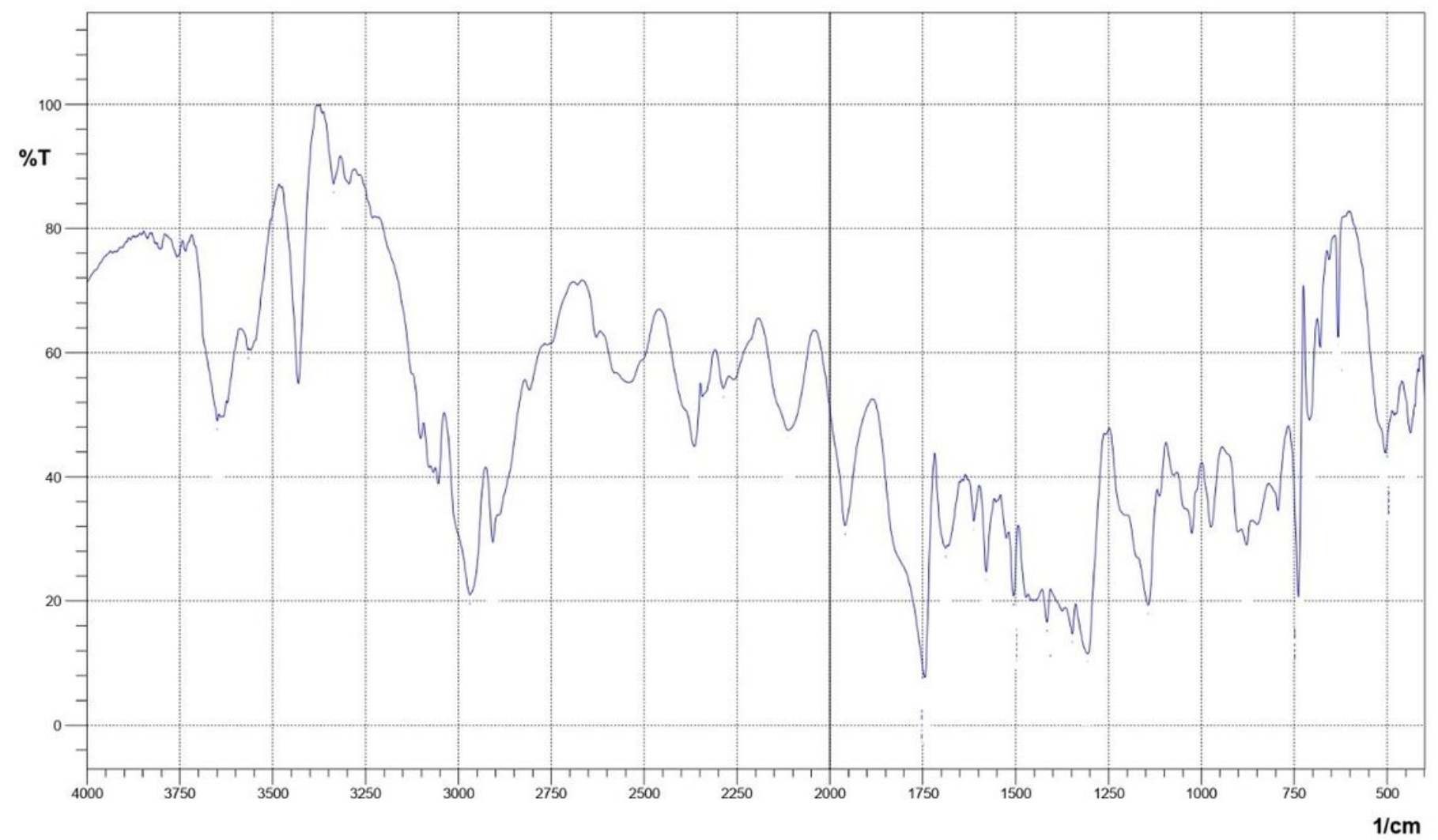

Figure 2

FT-IR spectra of PET membrane using PET resin as the polymer source

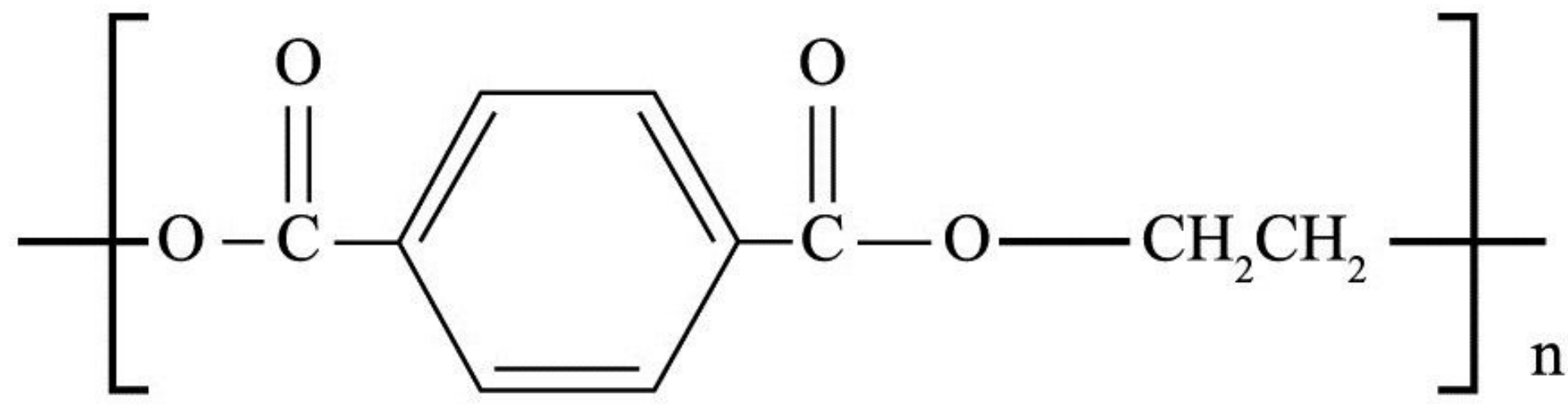

PET

Figure 3

Chemical structure of PET 


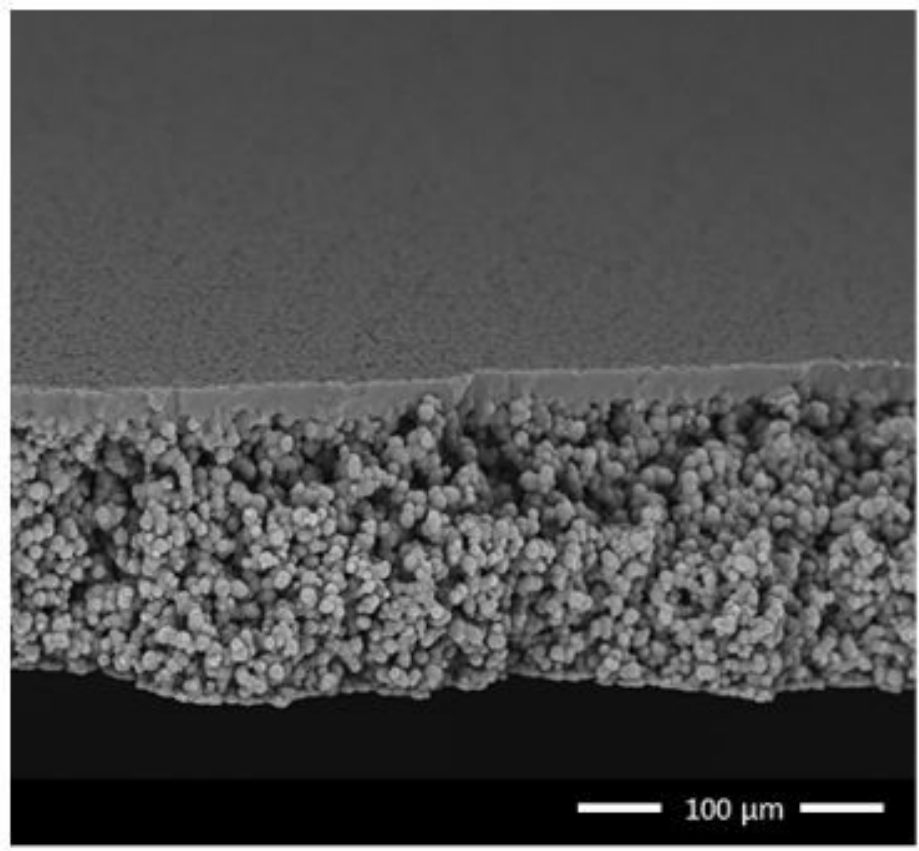

Membrane from PET bottle

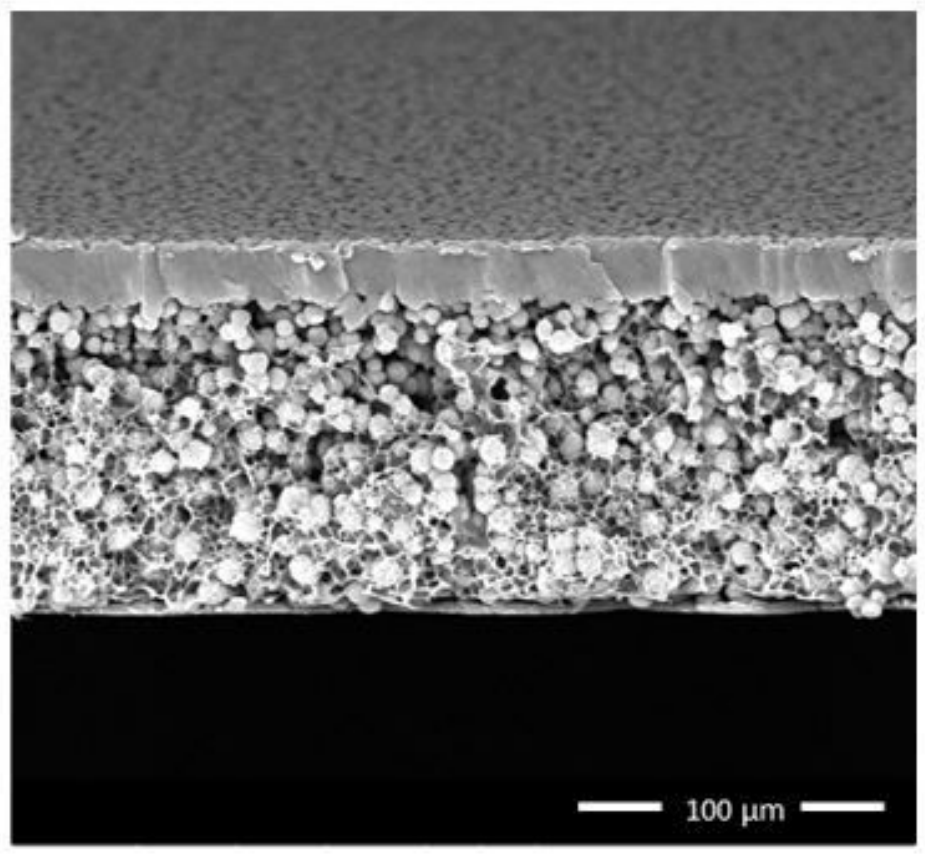

Membrane from PET resin

Figure 4

SEM photographs of the cross section and surface of the PET membrane from PET bottle and that from PET resin

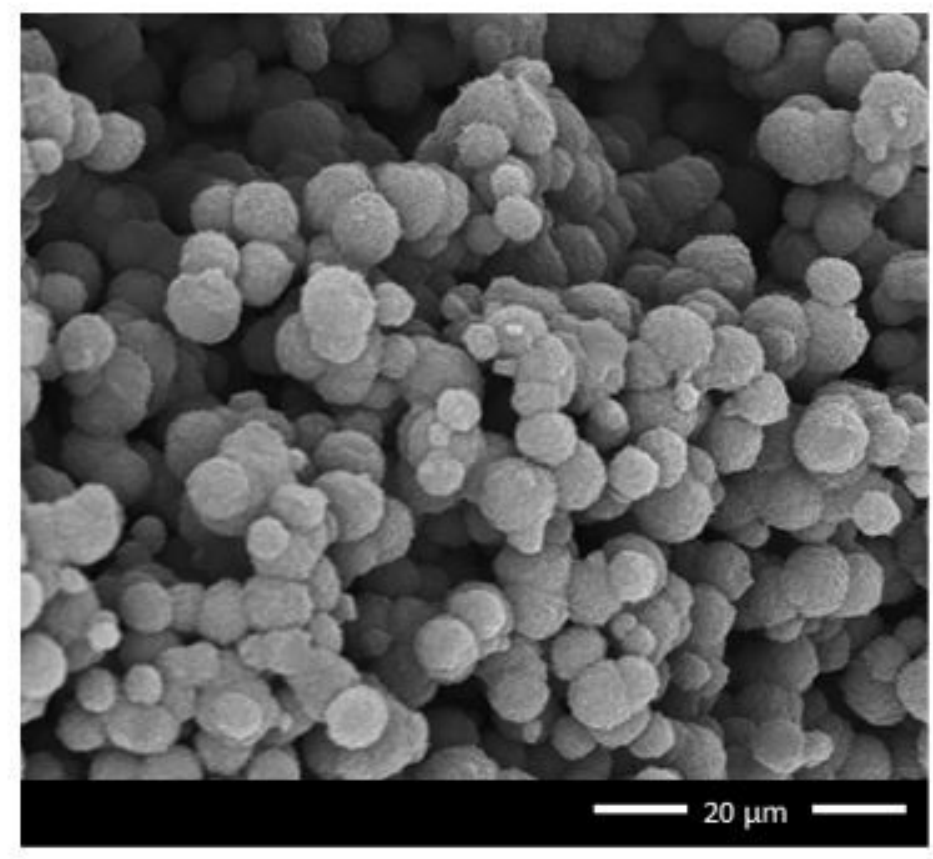

Membrane from PET bottle

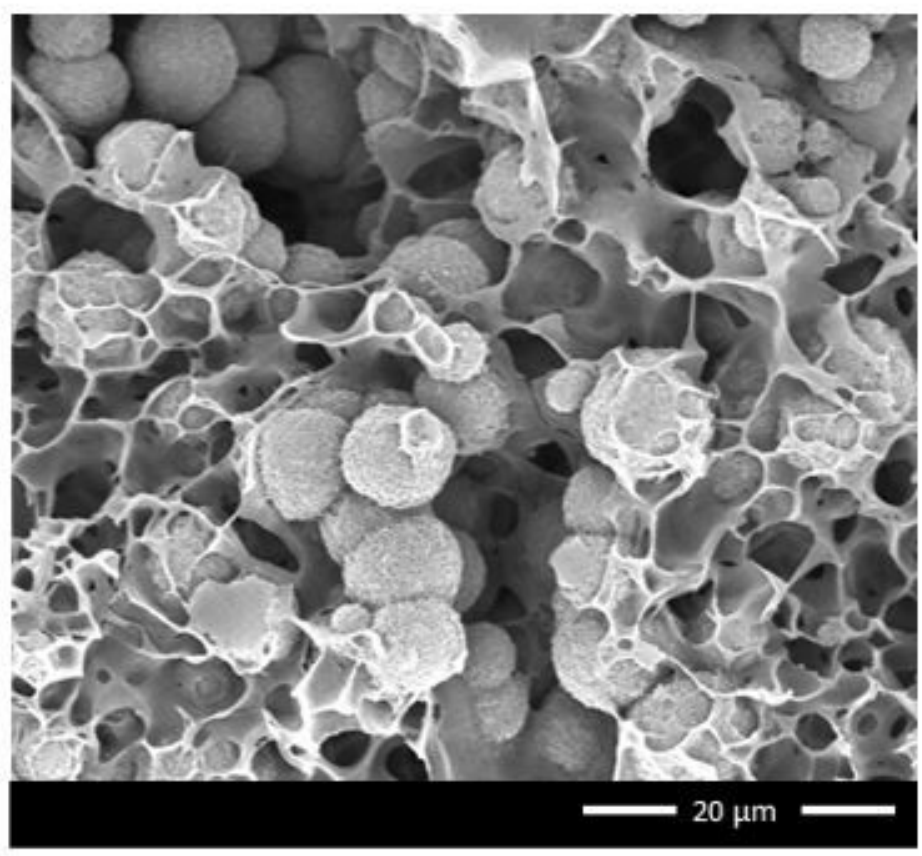

Membrane from PET resin

Figure 5 
SEM photographs of the cross section of the PET membrane from PET bottle and that from PET resin

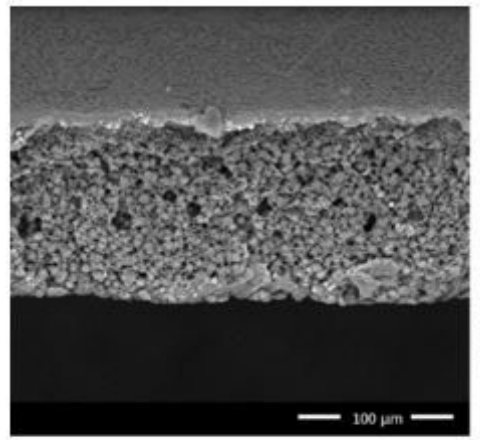

PET-PEG $4.95 w t \%$

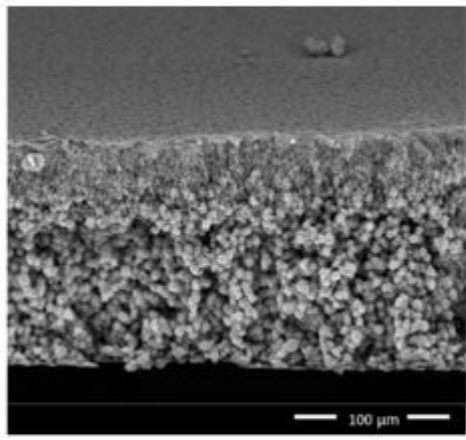

PET-PEG $5.88 w t \%$

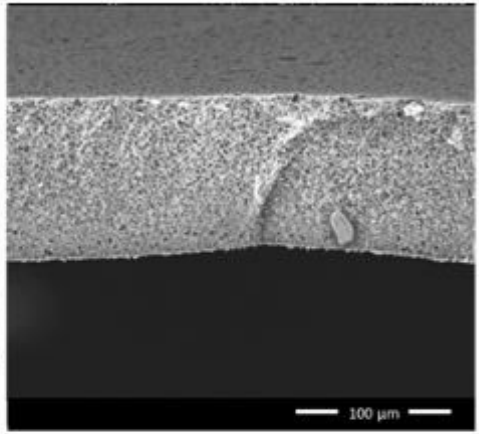

PET-PEG 7.69 wt\%

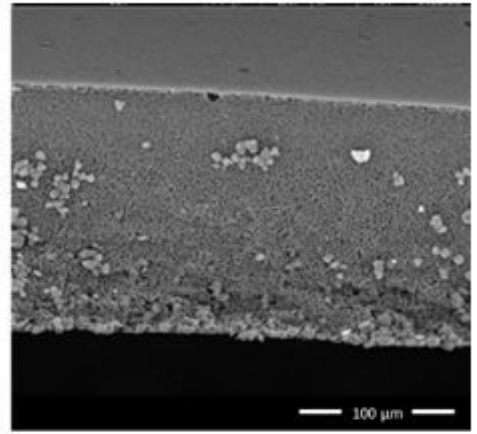

PET-PEG $11.11 w t \%$

Figure 6

SEM photographs of the cross section and surface of the PET membranes with different PEG 400 concentrations

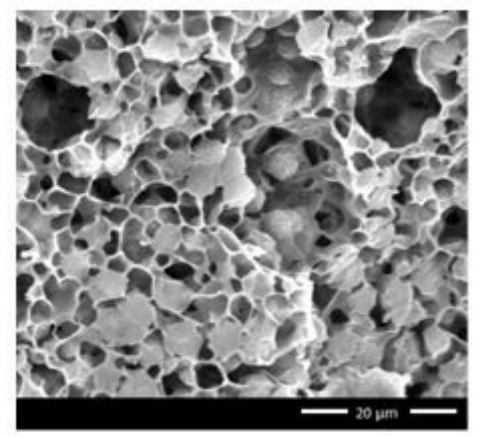

PET-PEG 4.95 wt $\%$

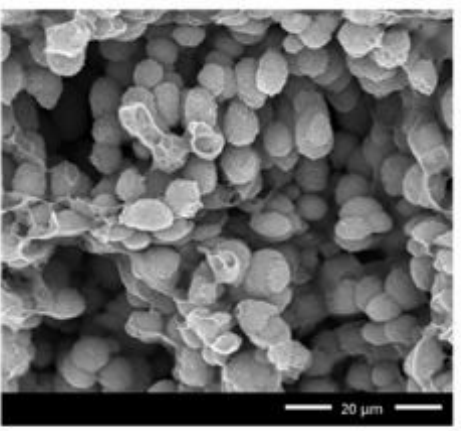

PET-PEG $5.88 w t \%$

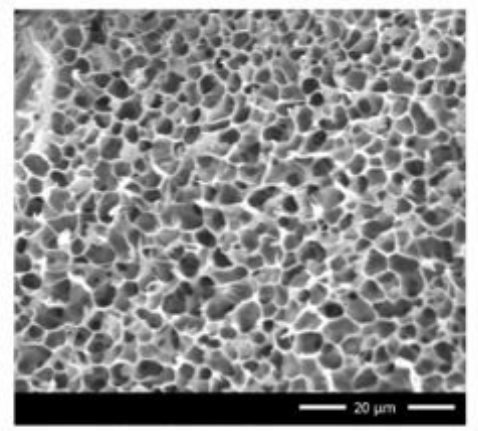

PET-PEG 7.69 wt\%

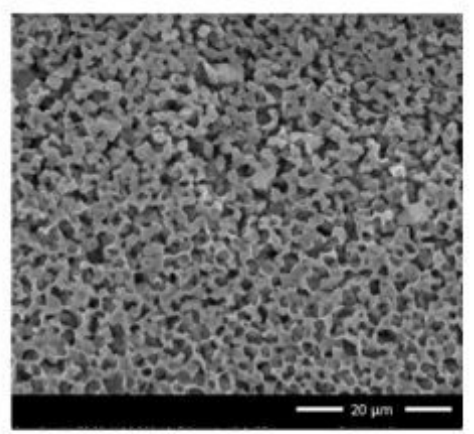

PET-PEG $11.11 w t \%$

\section{Figure 7}

SEM photographs of the cross section of the PET membranes with different PEG 400 concentrations 


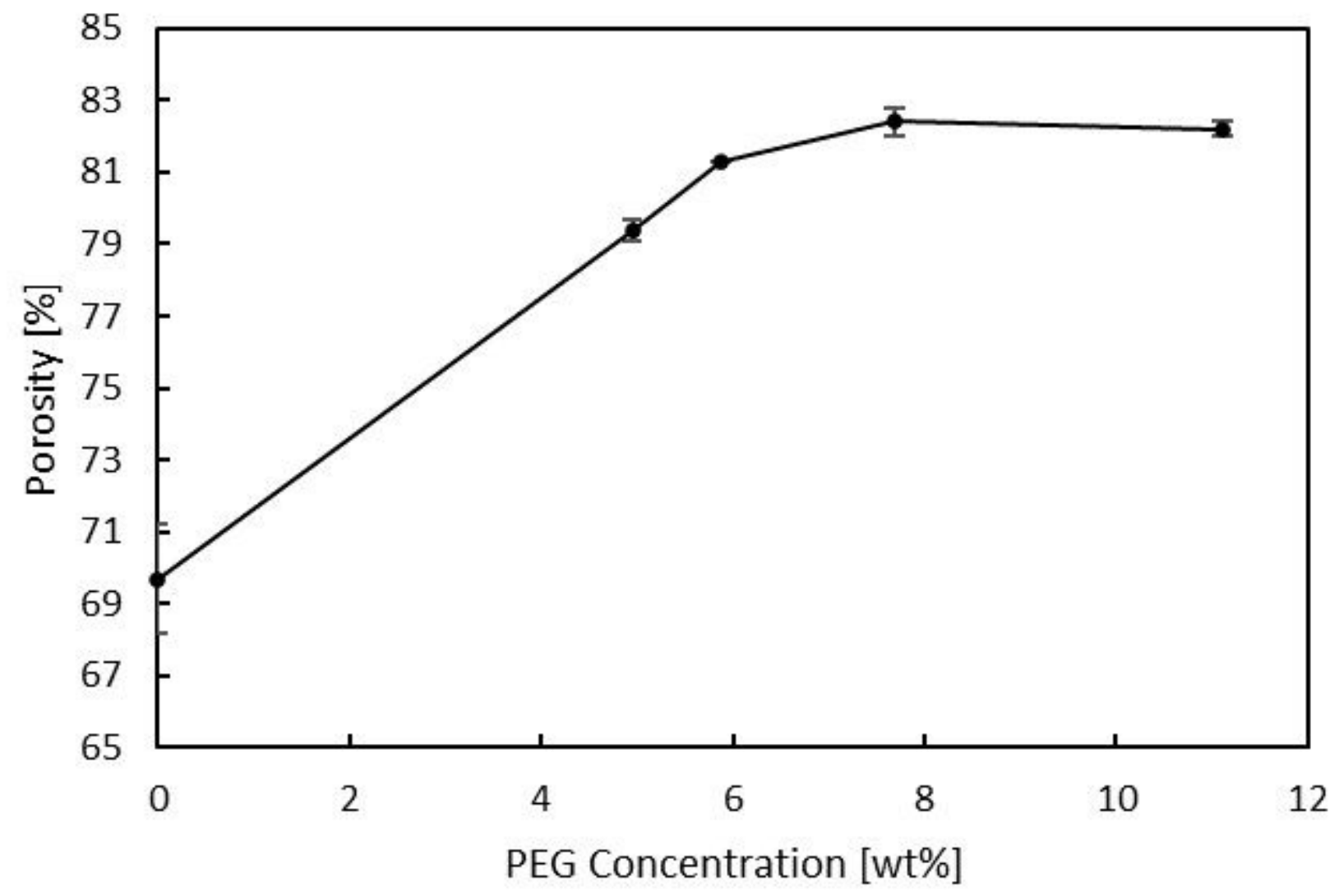

Figure 8

Porosity of the PET membranes as a function of PEG 400 concentration 


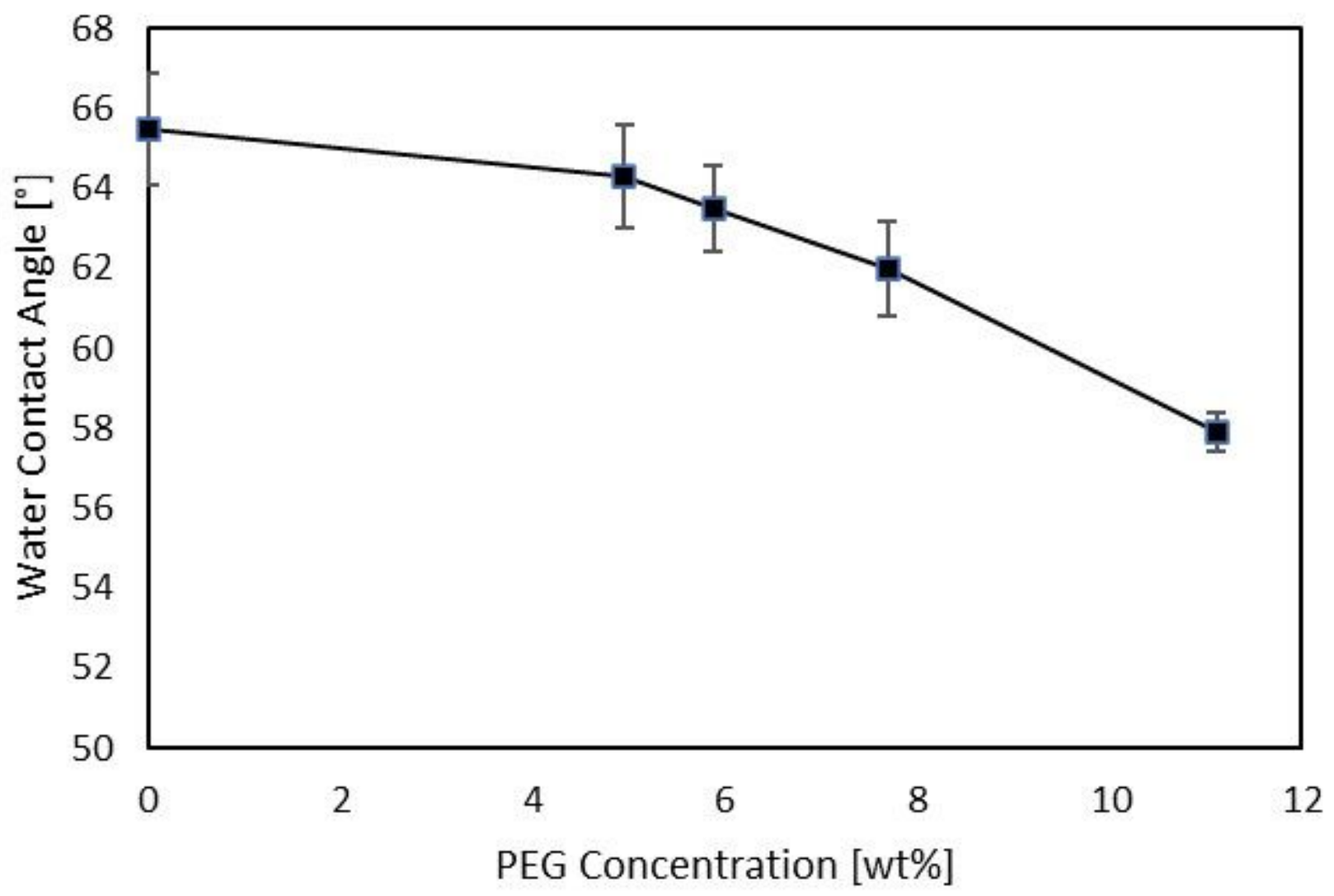

Figure 9

Water contact angle of the PET membranes as a function of PEG 400 concentration 


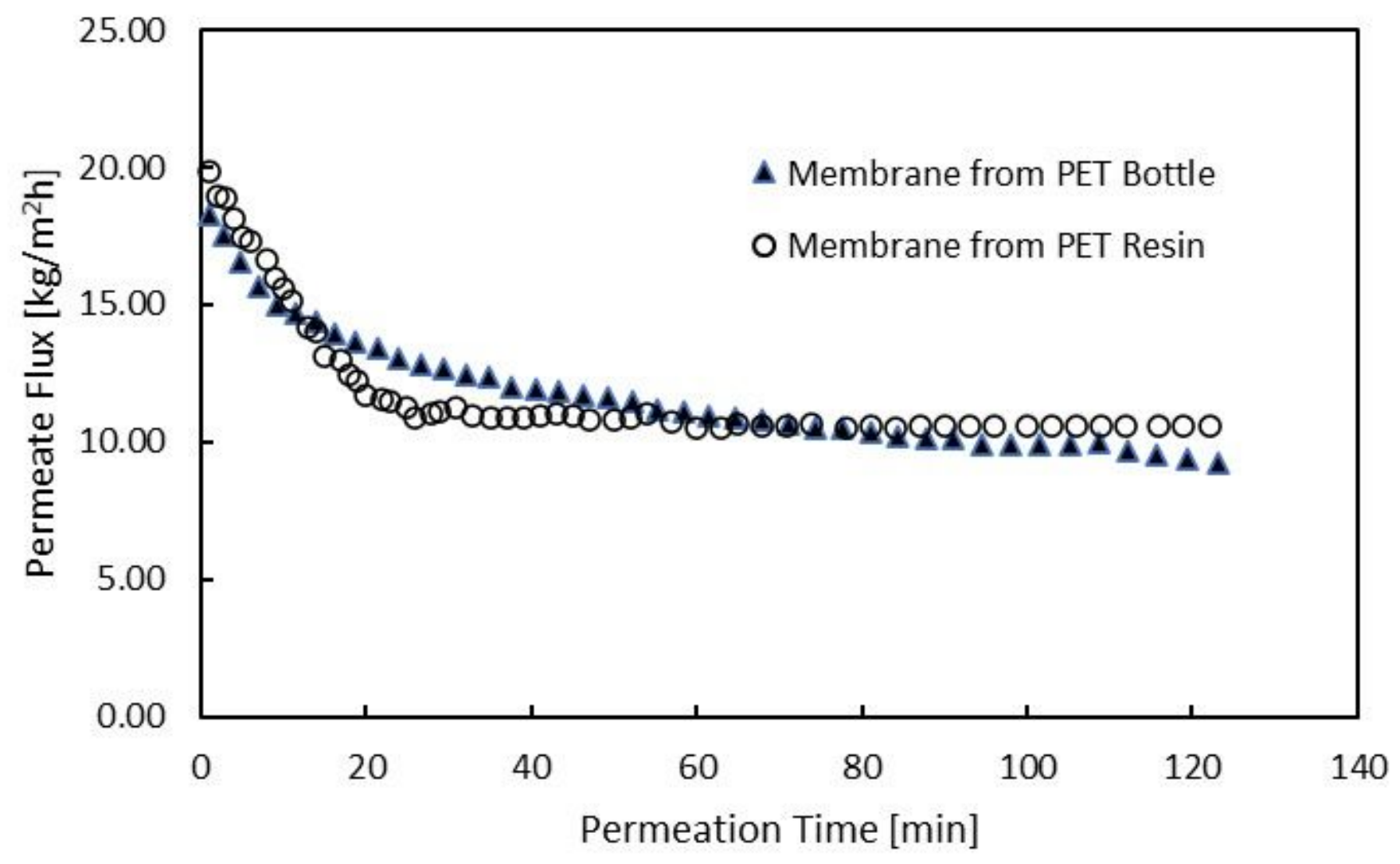

Figure 10

Comparison of permeate fluxes of the membranes prepared from PET bottle and PET resin with PEG 400 as the additive 


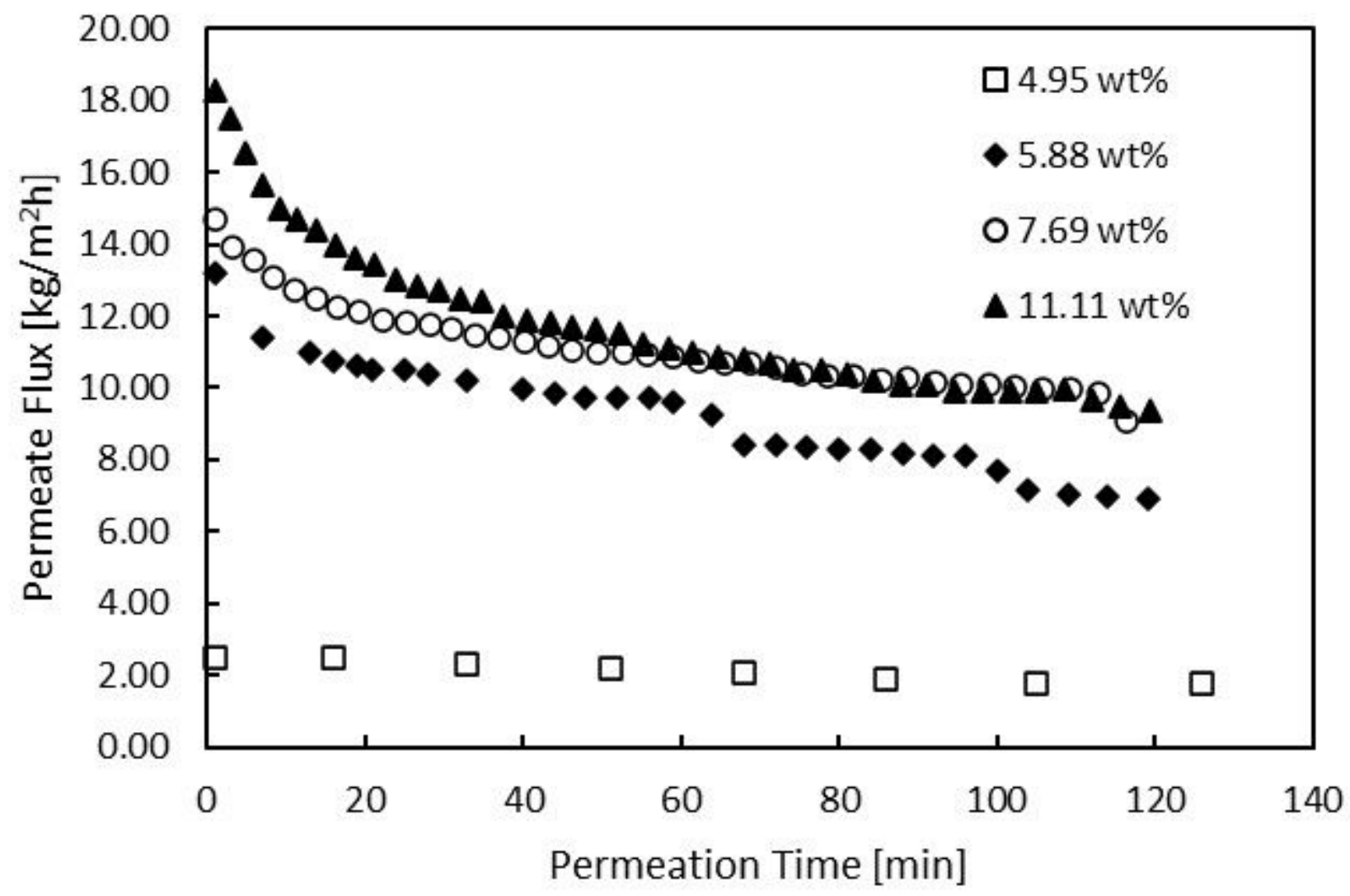

Figure 11

Permeate fluxes of the PET membranes with various PEG 400 concentrations 